\title{
Validity and reliability of EQ-5D-3L for breast cancer patients in Korea
}

\author{
Seon-Ha Kim", Min-Woo Jo ${ }^{2 *}$, Jong-Won Lee ${ }^{3,4}$, Hyeon-Jeong Lee ${ }^{2}$ and Jong Kyung Kim
}

\begin{abstract}
Background: Recently, breast cancer incidence and prevalence has been increasing. Patients' health related quality of life is important considerations in the treatment of breast cancer. The EQ-5D-3L is one of most popular instruments to measure health related quality of life. This study was aimed to evaluate the validity and reliability of EQ-5D-3L in post-operative breast cancer patients from Korea.

Methods: A total of 827 patients visiting the ambulatory cancer center of 1 tertiary hospital after breast cancer surgery self-administered the EQ-5D-3L and Functional Assessment of Cancer Therapy-Breast Cancer (FACT-B). We evaluated known-group validity using differences in the EQ-5D-3L index and EQ-VAS score according to demographic and clinical data. The discriminatory ability of the EQ-5D-3L was determined by comparing the mean FACT-B subscale scores between subjects with no problems and subjects with moderate or severe problems in each EQ-5D-3L dimension. Construct validity was evaluated by Pearson correlation coefficients among the EQ-5D-3L index and FACT-B subscales, respectively. Reliability was assessed in terms of test-retest reliability using Cohen's kappa value and intra-class correlation coefficient (ICC).

Results: The EQ-5D-3L index and EQ-VAS score were higher in the educated, current radiotherapy and unmarried groups. The correlation of EQ-5D-3L index and subscales for the FACT-B was highest in physical well-being $(r=0.553)$ and lowest in social well-being $(r=0.199)$. For reliability, the Kappa values' range was from 0.32 to 0.70 , and ICCS of the EQ-5D-3L index and EQ-VAS scores were 0.70 and 0.48 , respectively.
\end{abstract}

Conclusions: This study indicated that the EQ-5D-3L could be a valid health related quality of life instrument for postoperative breast cancer patients.

Keywords: Breast cancer, EQ-5D-3L, Health-related quality of life, FACT-B, Korea

\section{Background}

Breast cancer is the most frequently diagnosed cancer in females and the leading cause of cancer-related deaths in both economically developed and developing countries [1]. In Korea, the crude breast cancer incidence rate was 63.7 per 100,000 persons in 2011 and has been increasing since 1999 [2]. The 5-year survival rate for breast cancer patients has improved, with $91.3 \%$ reported between 2007 and 2011 in Korea [2]. Recent years have led to a range of treatments for breast cancer, and development of additional therapeutics is continually in progress.

\footnotetext{
* Correspondence: jominwoo@amc.seoul.kr

${ }^{2}$ Department of Preventive Medicine, University of Ulsan College of Medicine, 88, Olympicro 43-gil, Songpa-gu 138-736, Seoul, South Korea Full list of author information is available at the end of the article
}

Health-related quality of life (HRQoL) and traditional clinical outcomes (i.e., survival rate or tumor responses) are considered as significant outcomes of cancer care [3]. Tools to assess HRQoL are classified into disease-specific instruments and generic instruments. Preference-based instruments (the Health Utility Index $[4,5]$, the EuroQol 5D (EQ-5D-3L) [6], or the Short Form 6D [7]) are generic instrument generating utilities that yield a measure that combines both the length and quality of life [8]. Diseasespecific instruments can be more sensitive for detecting clinically important differences or changes in specific disease groups in general, although general instrument is occasionally not inferior to disease-specific instrument [9]. However, they do not compare HRQoL of patients with other diseases [8]. Resource allocation for health care has been a critical issue, not only for its effectiveness, but also 
for efficiency of care; hence, it is important for guiding healthcare policy.

The EQ-5D-3L, a generic preference-based instrument that is widely used to measure HRQoL, can be used to assign preference values to various health states [10]. Additionally, EQ-5D-3L is a unique instrument with quality weight tariffs for use in Korean populations [11]. The psychometric properties of the Korean EQ-5D-3L have been studied for rheumatic disease [12] and colon cancer [13] patients. However, studies on validity and reliability of the EQ-5D-3L in breast cancer patients in Korea are scarce [14]. Hence, we evaluated the validity and reliability of the EQ-5D-3L to measure the HRQoL in post-operative breast cancer patients from Korea.

\section{Methods}

\section{Subjects and settings}

A consecutive series of breast cancer patients who had surgery as a primary treatment at the ambulatory cancer center of 1 tertiary hospital in Seoul, Korea from February 2012 to May 2012, participated in this study. All participants provided informed written consent prior to taking our survey and a total of 1,002 subjects were consecutively recruited. The initial 150 recruited subjects were requested to complete an EQ-5D-3L questionnaire 1 week later via mail to assess the test-retest reliability of each patient. The survey was self-administered in the waiting room at the center with or without research nurse assistance. The Institutional Review Board of Asan Medical Center approved the study (IRB approval number: 2012-0010).

\section{Information}

Our questionnaire included requests for demographic information (age, sex, level of education, marital status, and occupation) and 2 HRQOL instruments (EQ-5D-3L and Functional Assessment of Cancer Therapy-Breast Cancer [FACT-B] version 4). Clinical information (the type of surgery, American Joint Committee on Cancer [AJCC] $7^{\text {th }}$ stage at diagnosis, duration of disease since diagnosis, and current treatment for breast cancer), was obtained from the cancer registry database of the center.

The EQ-5D-3L is an instrument widely used to measure and evaluate the general health status of a patient in 5 dimensions (mobility, self-care, usual activities, pain/discomfort, and anxiety/depression) with 3 levels as follows: 1 , no problems; 2 , some or moderate problems; and 3, extreme problems. The EQ-5D-3L provides a simple descriptive profile and a single index of health status [10]. The EQ-VAS records the respondent's self-rated health on a vertical, visual analogue scale where the endpoints are classified as follows: 'best imaginable health state' $=100$ and 'worst imaginable health state' $=0[10]$.
The FACT-B is a validated multi-dimensional selfreported questionnaire with a 36-item questionnaire that measures both the 27-item general QoL associated with cancer (Functional Assessment of Cancer Therapy General [FACT-G]) and an additional 9-item breast cancer-related QOL. The FACT-B includes the following subscales that measure physical well-being (PWB), functional well-being (FWB), emotional well-being (EWB), social/family well-being (SWB), and the breast cancer subscale (BCS). FACT-B total scores were calculated as the sum of the 5 subscales. FACT-G scores were calculated as the sum of the PWB, FWB, EWB, and SWB scores and FACT-B Trial Outcome Index (TOI) was calculated as the addition of the PWB, FWB and BCS scores $[15,16]$. This study used the Korean FACT-B version 4 that is validated [17] and a higher score indicated a better state.

\section{Analyses}

The proportion of patients reporting any problems in each EQ-5D-3L dimension and EQ-5D-3L index were presented. The EQ-5D-3L index was calculated using a Korean valuation set [11]. The EQ-5D-3L index ranged from -0.171 to 1 , and higher values indicated better health status. The FACT-B subscale scores were calculated in accordance with a scoring guideline provided by the Functional Assessment of Chronic Illness Therapy (FACIT) measurement system (www.facit.org/FACITOrg).

Differences in the EQ-5D-3L index and EQ-VAS score according to demographic and clinical data were compared using the Student's $t$-test or analysis of variance (ANOVA). In aspects of known group validity, we expected that the EQ-5D-3L index and EQ VAS would be lower for the following conditions: worse stage at diagnosis [18], current treatment group [18-20], shorter duration of disease since diagnosis [19, 21-24], older age group [16, 22], and lower education group [16, 18, 22].

The discriminatory ability of the EQ-5D-3L was determined by comparing the mean FACT-B subscale scores between subjects with no problems and subjects with moderate or severe problems in each EQ-5D-3L dimension. It was expected that the FACT-B subscale scores of subjects with no problem would be higher than those of subjects with any problem. The mean differences in the FACT-B subscale were compared using the Student's $t$-test. Discriminatory ability of the EQ-5D-5 L was considered acceptable when all hypothesized differences were significant.

Construct validity was evaluated by Pearson correlation coefficients among the EQ-5D-3L index, EQ-VAS, and FACT-B subscales. EQ-5D-3L index and FACT-G total scores were expected to be moderately or strongly correlated, because both instruments measured HRQoL. It was expected that the correlations between the 
EQ-5D-3L index and SWB subscale would be weaker than those of the other FACT-B subscales, because the EQ-5D-3L does not contain a social dimension. Construct validity was considered as acceptable when the hypotheses were satisfied.

Cohen's kappa statistic was used to assess the testretest reliability of each dimension for the EQ-5D-3L instrument. The kappa statistic calculates the degree of agreement in classification over that which would be expected by chance. There is no universally agreed-upon criteria of significant kappa value. We considered test-retest reliability of EQ-5D-5 L as acceptable if

Table 1 General and clinical characteristics of the study subjects

\begin{tabular}{|c|c|c|}
\hline Variables & $\mathrm{N}$ & (\%) \\
\hline \multicolumn{3}{|l|}{ Age, years } \\
\hline Less than 40 & 54 & $(6.5)$ \\
\hline $40-49$ & 263 & (31.8) \\
\hline $50-59$ & 385 & $(46.6)$ \\
\hline 60 or more & 125 & $(15.1)$ \\
\hline \multicolumn{3}{|l|}{ Level of education } \\
\hline Elementary school & 36 & $(4.4)$ \\
\hline Middle school graduate & 80 & $(9.7)$ \\
\hline High school graduate & 338 & $(40.9)$ \\
\hline College or higher & 371 & $(44.9)$ \\
\hline \multicolumn{3}{|l|}{ Marital status } \\
\hline Married & 692 & $(83.7)$ \\
\hline Widowed & 45 & $(5.4)$ \\
\hline Divorced & 39 & $(4.7)$ \\
\hline Unmarried & 51 & $(6.2)$ \\
\hline \multicolumn{3}{|l|}{ Surgery } \\
\hline Mastectomy & 303 & (36.6) \\
\hline Breast conserving surgery & 524 & $(63.4)$ \\
\hline \multicolumn{3}{|l|}{ AJCC $7^{\text {th }}$ stage at diagnosis } \\
\hline 0 & 136 & $(16.5)$ \\
\hline 1 & 361 & $(43.8)$ \\
\hline 2 & 260 & (31.5) \\
\hline 3 & 68 & $(8.2)$ \\
\hline \multicolumn{3}{|l|}{ Current treatment } \\
\hline Chemotherapy & 26 & $(3.2)$ \\
\hline Radiotherapy & 55 & $(6.7)$ \\
\hline \multicolumn{3}{|c|}{ Duration of disease since diagnosis } \\
\hline$<1$ year & 147 & $(17.8)$ \\
\hline $1-<2$ years & 104 & (12.6) \\
\hline $2-<3$ years & 106 & $(12.8)$ \\
\hline $3-<4$ years & 125 & $(15.1)$ \\
\hline $4-<5$ years & 91 & $(11.0)$ \\
\hline$\geq 5$ years & 254 & $(30.7)$ \\
\hline
\end{tabular}

kappa value was higher than 0.4 in each dimension [25]. The intraclass correlation coefficient (ICC) [26] was used to assess the reliability of the EQ-5D-3L index and EQ-VAS score. We considered that $>0.5$ ICC was acceptable.

\section{Results}

Among 1,002 recruited patients with breast cancer, 175 patients were excluded from this analysis: 13 duplicated, 2 with missing EQ-5D-3L data, and 160 patients who did not merge into the cancer registry data. Thus, a total of 827 patients were included in the study cohort. Among 150 participants who completed a second survey 1 week later, 67 participants replied and 54 subjects were used for test-retest reliability after excluding 13 participants for whom clinical information was not available. Demographic characteristics of the survey participants were shown in Table 1. All study participants were

Table 2 Distribution of EQ-5D-3L problem reporting and FACTB scores

\begin{tabular}{|c|c|c|c|}
\hline EQ-5D-3L dimension & Level $^{a}$ & $\mathrm{~N}$ & (\%) \\
\hline \multirow[t]{3}{*}{ Mobility } & 1 & 760 & $(91.9)$ \\
\hline & 2 & 67 & $(8.1)$ \\
\hline & 3 & 0 & $(0.0)$ \\
\hline \multirow[t]{3}{*}{ Self-care } & 1 & 791 & $(95.7)$ \\
\hline & 2 & 33 & $(4.0)$ \\
\hline & 3 & 3 & $(0.4)$ \\
\hline \multirow[t]{3}{*}{ Usual activities } & 1 & 720 & $(87.1)$ \\
\hline & 2 & 105 & $(12.7)$ \\
\hline & 3 & 2 & $(0.2)$ \\
\hline \multirow[t]{3}{*}{ Pain/discomfort } & 1 & 467 & $(56.5)$ \\
\hline & 2 & 351 & $(42.4)$ \\
\hline & 3 & 9 & $(1.1)$ \\
\hline \multirow[t]{3}{*}{ Anxiety/depression } & 1 & 484 & $(58.5)$ \\
\hline & 2 & 334 & $(40.4)$ \\
\hline & 3 & 0 & $(1.1)$ \\
\hline FACT-B scale scores (possible range) & & Mean & (SD) \\
\hline Physical well-being (0-28) & & 24.0 & $(4.3)$ \\
\hline Social well-being (0-28) & & 17.0 & $(6.9)$ \\
\hline Functional well-being (0-28) & & 19.3 & $(6.4)$ \\
\hline Emotional well-being (0-24) & & 18.3 & $(4.0)$ \\
\hline Breast cancer subscale (0-36) & & 23.3 & $(5.4)$ \\
\hline FACT-G (0-108) & & 78.7 & $(15.8)$ \\
\hline FACT-B Trial Outcome Index (0-92) & & 66.7 & $(12.3)$ \\
\hline FACT-B total score (0-144) & & 102.1 & $(19.0)$ \\
\hline
\end{tabular}

FACT-B functional assessment of cancer therapy-Breast cancer $F A C T-G$ functional assessment of cancer therapy-General Higher scores on the FACT-B scales indicate better quality of life ${ }^{\mathrm{a}}$ 1: no problem; 2: moderate problems; 3: extreme problems 
female with a mean age of 52.1 years. Most patients were married. The number of participants who had undergone breast-conserving surgery was $524(63.4 \%)$.

The proportion of patients reporting any problems of the EQ-5D-3L and the FACT-B subscale score distribution in the study participants was shown in Table 2 . The proportion of patients reporting any problems was relatively higher in the pain/discomfort and anxiety/depression dimensions at $43.5 \%$ and $41.5 \%$, respectively. The mean FACT-G score was 78.7 (SD 15.8) and mean TOI was 66.7 (12.3). The EQ-5D-3L index and VAS score according to demographic and clinical features were shown in Table 3. In the highly educated and unmarried group, and not in current radiotherapy group,

Table 3 EQ-5D-3L scores according to general and clinical characteristics of the study patients

\begin{tabular}{|c|c|c|c|c|c|c|c|}
\hline \multirow{2}{*}{$\begin{array}{l}\text { Variables } \\
(n=827)\end{array}$} & \multirow[b]{2}{*}{$\mathrm{n}$} & \multicolumn{3}{|c|}{ EQ-5D-3L index } & \multicolumn{3}{|c|}{ EQ-VAS } \\
\hline & & $\bar{M}$ & SD & p-value ${ }^{*}$ & $\bar{M}$ & SD & $p$-value \\
\hline \multicolumn{8}{|l|}{ Age group (year) } \\
\hline Less than 40 & 54 & 0.918 & $(0.071)$ & 0.448 & 76.3 & $(18.0)$ & 0.338 \\
\hline $40-49$ & 263 & 0.921 & $(0.075)$ & & 77.8 & $(17.5)$ & \\
\hline $50-59$ & 385 & 0.912 & $(0.092)$ & & 78.5 & $(16.3)$ & \\
\hline 60 or more & 125 & 0.907 & $(0.105)$ & & 80.6 & (15.8) & \\
\hline \multicolumn{8}{|l|}{ Level of education (year) } \\
\hline$\leq 6$ & 36 & 0.864 & $(0.099)$ & $<0.001$ & 81.9 & $(16.0)$ & 0.629 \\
\hline $7-9$ & 80 & 0.880 & $(0.100)$ & & 77.7 & $(16.8)$ & \\
\hline $10-12$ & 338 & 0.916 & $(0.090)$ & & 78.2 & $(17.9)$ & \\
\hline$\geq 13$ & 371 & 0.925 & $(0.079)$ & & 78.4 & (15.8) & \\
\hline \multicolumn{8}{|l|}{ Marital status } \\
\hline Married & 692 & 0.917 & $(0.086)$ & 0.045 & 78.6 & $(16.7)$ & 0.697 \\
\hline Widowed & 45 & 0.901 & $(0.097)$ & & 79.0 & $(15.4)$ & \\
\hline Divorced & 39 & 0.879 & $(0.125)$ & & 78.1 & $(20.0)$ & \\
\hline Unmarried & 51 & 0.921 & $(0.072)$ & & 75.7 & $(16.2)$ & \\
\hline \multicolumn{8}{|l|}{ Surgery } \\
\hline Mastectomy & 303 & 0.915 & $(0.088)$ & 0.872 & 78.8 & $(16.9)$ & 0.678 \\
\hline Breast conserving surgery & 524 & 0.914 & $(0.088)$ & & 78.2 & (16.6) & \\
\hline \multicolumn{8}{|l|}{ AJCC $7^{\text {th }}$ stage at diagnosis } \\
\hline 0 & 136 & 0.925 & $(0.081)$ & 0.083 & 78.2 & $(16.3)$ & 0.929 \\
\hline 1 & 361 & 0.918 & $(0.093)$ & & 78.1 & (16.6) & \\
\hline 2 & 260 & 0.909 & $(0.083)$ & & 79.0 & $(16.4)$ & \\
\hline 3 & 68 & 0.895 & $(0.088)$ & & 78.4 & $(19.1)$ & \\
\hline \multicolumn{8}{|l|}{ Current chemotherapy } \\
\hline No & 793 & 0.915 & $(0.088)$ & 0.361 & 78.5 & (16.6) & 0.602 \\
\hline Yes & 26 & 0.899 & $(0.081)$ & & 76.7 & $(18.9)$ & \\
\hline \multicolumn{8}{|l|}{ Current radiotherapy } \\
\hline No & 764 & 0.917 & $(0.087)$ & 0.001 & 78.8 & $(16.3)$ & 0.047 \\
\hline Yes & 55 & 0.877 & $(0.102)$ & & 72.8 & $(21.0)$ & \\
\hline \multicolumn{8}{|c|}{ Duration of disease since diagnosis } \\
\hline$<1$ year & 147 & 0.893 & $(0.090)$ & 0.003 & 77.5 & $(18.1)$ & 0.385 \\
\hline $1-<2$ years & 104 & 0.903 & $(0.084)$ & & 76.7 & $(16.7)$ & \\
\hline $2-<3$ years & 106 & 0.921 & $(0.093)$ & & 78.2 & $(17.5)$ & \\
\hline $3-<4$ years & 125 & 0.914 & $(0.090)$ & & 78.5 & $(16.1)$ & \\
\hline $4-<5$ years & 91 & 0.934 & $(0.066)$ & & 81.8 & $(13.9)$ & \\
\hline$\geq 5$ years & 254 & 0.922 & $(0.090)$ & & 78.6 & $(16.9)$ & \\
\hline
\end{tabular}

${ }^{*} p<0.05$ by Student's $t$-test or ANOVA 
Table 4 FACT-B scales and summary measurements by EQ-5D-3L dimension and level

\begin{tabular}{lllllllllll}
\hline Dimension & Level $^{a}$ & $\mathrm{n}$ & $\mathrm{PWB}$ & SWB & EWB & FWB & FACTG & BCS & TOI & FACT-B total \\
\hline Mobility & 1 & 760 & $24.4^{* *}$ & $17.1^{* *}$ & $18.5^{* *}$ & $19.6^{* *}$ & $79.7^{* *}$ & $23.7^{* *}$ & $67.7^{* *}$ & $103.4^{* *}$ \\
& 2 or 3 & 67 & 19.7 & 14.9 & 16.8 & 16.1 & 67.6 & 19.6 & 55.5 & 87.3 \\
Self-care & 1 & 791 & $24.2^{* *}$ & $17.1^{*}$ & $18.4^{*}$ & $19.6^{* *}$ & $79.4^{* *}$ & $23.5^{* *}$ & $67.3^{* *}$ & $102.9^{* *}$ \\
& 2 or 3 & 36 & 20.0 & 14.1 & 17.0 & 13.7 & 64.0 & 20.5 & 53.5 & 84.4 \\
Usual activities & 1 & 720 & $24.7^{* *}$ & $17.3^{* *}$ & $18.6^{* *}$ & $20.0^{* *}$ & $80.7^{* *}$ & $23.8^{* *}$ & $68.5^{* *}$ & $104.5^{* *}$ \\
& 2 or 3 & 107 & 19.8 & 14.6 & 16.3 & 14.5 & 65.4 & 20.0 & 54.4 & 85.5 \\
Pain/discomfort & 1 & 467 & $25.4^{* *}$ & $17.5^{*}$ & $18.9^{* *}$ & $20.4^{* *}$ & $82.3^{* *}$ & $24.4^{* *}$ & $70.2^{* *}$ & $106.7^{* *}$ \\
& 2 or 3 & 360 & 22.2 & 16.3 & 17.6 & 17.9 & 74.1 & 22.0 & 62.1 & 96.0 \\
Anxiety/depression & 1 & 484 & $25.3^{* *}$ & $18.0^{* *}$ & $20.0^{* *}$ & $21.2^{* *}$ & $84.6^{* *}$ & $24.9^{* *}$ & $71.4^{* *}$ & $109.5^{* *}$ \\
& 2 or 3 & 343 & 22.2 & 15.5 & 15.9 & 16.6 & 70.4 & 21.1 & 60 & 91.6
\end{tabular}

FACT-B functional assessment of cancer therapy-Breast cancer, FACT-G functional assessment of cancer therapy-general, PWB physical well-being, FWB functional well-being, EWB emotional well-being, SWB social/family well-being (SWB), BCS breast cancer subscale, TOI Trial outcome index

${ }^{a}$, no problem; 2,moderate problems; 3,extreme problems

${ }^{*} p<0.05$ by Student's $t$-test

$p<0.001$ by Student's $t$-test

the EQ-5D-3L index scores were higher than corresponding scores of the other groups. A worse stage at the time of diagnosis was associated with lower HRQoL scores; however, this trend did not reach the threshold for statistical significance. By post-hoc analysis, individuals with $<1$ year since the time of diagnosis had a significantly lower EQ-5D-3L index as compared with those who had $>4$ years since their diagnosis. The EQVAS score were not significantly different according to demographic and clinical characteristics.

FACT-B subscale scores and summary measurements by dimension and level of the EQ-5D-3L were shown in Table 4. All FACT-B subscale scores and combined index of subjects with no problem were significantly higher than those of subjects with any problem in all EQ-5D-3L dimensions. Difference in PWB scores was larger than other FACT-B subscales in mobility dimension, whereas difference in PWB scores was larger in self-care and usual activities dimensions. Difference in

Table 5 Correlations between the EQ-5D-3L index, EQ-VAS score, and FACT-B scores

\begin{tabular}{lcc}
\hline FACT-B scores & EQ-5D-3L index & EQ VAS \\
\hline Physical well-being & 0.553 & 0.447 \\
Social well-being & 0.199 & 0.170 \\
Emotional well-being & 0.400 & 0.371 \\
Functional well-being & 0.377 & 0.312 \\
Breast cancer subscale & 0.390 & 0.323 \\
FACTG & 0.488 & 0.414 \\
Trial Outcome Index & 0.557 & 0.456 \\
FACT B total & 0.516 & 0.436 \\
\hline
\end{tabular}

FACT-B functional assessment of cancer therapy-breast cancer, FACT-G functional assessment of cancer therapy-general

Pearson's correlation coefficient, all p-values were $<0.001$
EWB scores was the largest in the anxiety/depression dimension. Table 5 showed correlation coefficients among the EQ-5D-3L index, EQ-VAS score, and FACT-B scores. TOI scores showed the highest correlation with both the EQ-5D-3L index and EQ-VAS scores at 0.557 and 0.456 , respectively, and the SWB scores showed the lowest correlation with the EQ-5D-3L index. Rates of agreements in the EQ-5D-3L dimensions ranged from 85.2 to $96.3 \%$ across dimensions. Kappa statistics ranged from 0.32 in mobility to 0.70 in pain/discomfort and anxiety/depression dimensions. ICCs of the EQ-5D-3L index and EQ-VAS scores were 0.70 and 0.48 , respectively (Table 6).

\section{Discussion}

In this study, we aimed to assess the validity and reliability of EQ-5D-3L for measuring HRQoL in post-operative breast cancer patients. Our findings supported the validity of the EQ-5D-3L index. Values for this index were lower in the current radiation therapy, shorter duration of disease since diagnosis, and low education groups.

Table 6 Test-retest reliability of the EQ-5D-3L

\begin{tabular}{lll}
\hline Dimension & $\begin{array}{l}\text { Kappa statistics }(95 \% \mathrm{Cl}) \\
\text { all patients }(\mathrm{n}=54)\end{array}$ & $\begin{array}{l}\text { Agreement } \\
\text { rate }(\%)\end{array}$ \\
\hline Mobility & $0.32(-0.18-0.93)$ & 94.4 \\
Self-care & $0.49(-0.11-1.00)$ & 96.3 \\
Usual activities & $0.46(0.13-0.80)$ & 87.0 \\
Pain/discomfort & $0.70(0.51-0.89)$ & 85.2 \\
Anxiety/depression & $0.70(0.52-0.89)$ & 85.2 \\
Intraclass correlation coefficient $(95 \% \mathrm{Cl})$ & \\
EQ-5D-3L index & $0.70(0.54-0.82)$ & \\
EQ-VAS & $0.48(0.25-0.66)$ & \\
\hline
\end{tabular}


Most of known-group validity features fulfilled our hypothesis. EQ-5D-3L indexes were lower for progressive stages at diagnosis and in the current chemotherapy group, although the differences in the EQ-5D-3L index between groups were not statistically significant. Our results corroborated the findings of Chae and Seo that patients who are younger, more highly educated, and with a longer time since diagnosis have a higher HRQoL [22]. HRQoL score differences by age group were not consistent with previous reports of HRQoL measurements in breast cancer patients [16, 22, 23]. Age has different impacts on HRQoL domains. Ahn et al's study on breast cancer survivors showed better social and emotional function but poorer physical function with increasing age [24].

The FACT-B subscale scores for problem reporting in each EQ-5D-3L dimension were significantly different in the current analysis. The EQ-5D-3L index was moderately correlated with FACT-B subscale scores, ranging from 0.377 at FWB to 0.553 at PWB subscales, except for SWB. This finding was similar to those of Lee et al. who studied patients with breast cancer in Singapore [26]. In that study, a correlation between the EQ-5D-3L index and FACT-B subscales was the lowest at 0.11 on the SWB subscales and the highest at 0.66 on the PWB subscales [26].

Reliability of EQ-5D-3L in this study was inconclusive. Kappa values for EQ-5D-3L dimensions varied depending on domain and confidence intervals of kappa values were wide in mobility, self-care and usual activities. The ICCs of the EQ-5D-3L index was reasonable but EQVAS were somewhat low. Kappa values on mobility dimensions were the lowest at 0.32 , but showed some agreement with the Landis and Koch criteria [25] at an agreement rate of $94.4 \%$. Low reliability statistics could be due to small sample size, change of health states between 2 time periods, and high proportion of no problem in mobility, self-care and usual activities dimensions. In the previous Singapore study, ICCs for the EQ-5D-3L index were reported to as 0.81 in the English version and 0.69 in the Chinese version [27]. Similarly, another Korean study of colorectal cancer patients reported kappa values for the EQ-5D-3L dimensions ranging from 0.32 to 0.56 and the ICC of the EQ-5D-3L index of 0.55 [13]. Compared to our present study, an earlier Taiwan study on cervical cancer patients reported somewhat higher kappa values for the EQ-5D-3L dimensions and the ICC of the EQ-5D-3L index [28].

The findings of the present study cannot be generalized since only postoperative breast cancer patients at 1 tertiary hospital were enrolled. Another limitation was that we did not investigate patient recurrence status, time since treatment completion, performance status at the visit day, or comorbidity. Because these parameters could affect the HRQoL, more comprehensive data are needed in the future to assess the psychometric properties of the HRQoL instruments. In addition, we did not assess the responsiveness of the EQ-5D-3L in breast cancer interventions; hence, further studies are warranted. Lastly, we did not reassess physical status at retest period, thus evidence on test-retest reliability was inconclusive.

\section{Conclusion}

In conclusion, we showed that the EQ-5D-3L could be a valid instrument for measuring the HRQoL of postoperative breast cancer patients in South Korea. However, reliability of the EQ-5D-3L is not conclusive and needs further research.

\section{Abbreviations \\ ANOVA: analysis of variance; BCS: breast CANCER subscale; EWB: emotional well-being; FACT-B: Functional Assessment of Cancer Therapy-Breast Cancer; FACT-G: Functional Assessment of Cancer Therapy - General; FWB: Functional well-being; HRQoL: health-related quality of life; ICC: intra-class correlation coefficient; PWB: physical well-being; SWB: social/family well-being.}

\section{Competing interests}

The authors declare that they have no competing interests.

\section{Authors' contributions}

All authors contributed to the conception and design of the study and the interpretation of the results. MWJ was responsible for data acquisition. SHK analyzed the data and was involved in drafting the manuscript. MWJ, JWL and JKK were involved in revising the manuscript to ensure its critically important content. All authors have read and approved the final manuscript.

\section{Acknowledgements}

This study supported by Bayer Korea.

\section{Author details}

${ }^{1}$ Department of Nursing, Dankook University, Cheonan, South Korea. ${ }^{2}$ Department of Preventive Medicine, University of Ulsan College of Medicine, 88, Olympicro 43-gil, Songpa-gu 138-736, Seoul, South Korea. ${ }^{3}$ Department of Breast and Endocrine Surgery, Asan Medical Center, Seoul, South Korea. ${ }^{4}$ Department of Surgery, University of Ulsan College of Medicine, Seoul, South Korea.

Received: 8 July 2015 Accepted: 15 December 2015

Published online: 23 December 2015
References
1. Jemal A, Bray F, Center MM, Ferlay J, Ward E, Forman D. Global cancer statistics. CA Cancer J Clin. 2011;61:69-90.
2. The Korea Central Cancer Registry, National Cancer Center, Ministry of Health and Welfare. Annual report of cancer statistics in Korea in 2011. Seoul: Ministry of Health and Welfare; 2013.
3. Nayfield SG, Ganz PA, Moinpour CM, Cella DF, Hailey BJ. Report from a National Cancer Institute (USA) workshop on quality of life assessment in cancer clinical trials. Qual Life Res. 1992;1:203-10.
4. Torrance GW, Feeny DH, Furlong WJ, Barr RD, Zhang Y, Wang Q. Multiattribute utility function for a comprehensive health status classification system. Health Utilities Index Mark 2. Med Care. 1996;34:702-22.
5. Feeny D, Furlong W, Torrance GW, Goldsmith $\mathrm{CH}$, Zhu Z, DePauw S, et al. Multiattribute and single-attribute utility functions for the health utilities index mark 3 system. Med Care. 2002;40:113-28.
6. Brooks R. EuroQol: the current state of play. Health Policy. 1996;37:53-72.
7. Brazier J, Roberts J, Deverill M. The estimation of a preference-based measure of health from the SF-36. J Health Econ. 2002;21:271-92. 
8. Drummond MF, Sculpher MJ, Torrance GW, O'Brien BJ, Stoddart GL. Methods for the Economic Evaluation of Health Care Programme. New York: Oxford University Press; 2005.

9. Lee CF, Luo N, Ng R, Wong NS, Yap YS, Lo SK, et al. Comparison of the measurement properties between a short and generic instrument, the 5-level EuroQoL Group's 5-dimension (EQ-5D-5 L) questionnaire, and a longer and disease-specific instrument, the Functional Assessment of Cancer Therapy-Breast (FACT-B), in Asian breast cancer patients. Qual Life Res. 2013;22:1745-51.

10. Brooks R, Rabin R, de Charro F. The Measurement and Valuation of Health Status Using Eq-5D: A European Perspective: Evidence from the Eurogol Biomed Research Programme. Dordrecht, The Netherlands. London: Kluwer Academic Publishers; 2003

11. Lee YK, Nam HS, Chuang LH, Kim KY, Yang HK, Kwon IS, et al. South Korean time trade-off values for EQ-5D health states: modeling with observed values for 101 health states. Value Health. 2009;12:1187-93.

12. Kim MH, Cho YS, Uhm WS, Kim S, Bae SC. Cross-cultural adaptation and validation of the Korean version of the EQ-5D in patients with rheumatic diseases. Qual Life Res. 2005;14:1401-6.

13. Kim SH, Hwang JS, Kim TW, Hong YS, Jo MW. Validity and reliability of the EQ-5D for cancer patients in Korea. Support Care Cancer. 2012;20:3155-60.

14. Kim SH, Kim HJ, Lee Sl, Jo MW. Comparing the psychometric properties of the EQ-5D-3L and EQ-5D-5 L in cancer patients in Korea. Qual Life Res. 2012;21:1065-73.

15. Brady MJ, Cella DF, Mo F, Bonomi AE, Tulsky DS, Lloyd SR, et al. Reliability and validity of the Functional Assessment of Cancer Therapy-Breast quality-of-life instrument. J Clin Oncol. 1997;15:974-86.

16. Park BW, Lee S, Lee AR, Lee KH, Hwang SY. Quality of Life Differences between Younger and Older Breast Cancer Patients. J Breast Cancer. 2011;14:112-8.

17. Yoo HJ, Ahn SH, Eremenco S, Kim H, Kim WK, Kim SB, et al. Korean translation and validation of the functional assessment of cancer therapy-breast (FACT-B) scale version 4. Qual Life Res. 2005;14:1627-32.

18. Lu W, Cui Y, Zheng Y, Gu K, Cai H, Li Q, et al. Impact of newly diagnosed breast cancer on quality of life among Chinese women. Breast Cancer Res Treat. 2007:102:201-10

19. Lu W, Cui Y, Chen X, Zheng Y, Gu K, Cai H, et al. Changes in quality of life among breast cancer patients three years post-diagnosis. Breast Cancer Res Treat. 2009;114:357-69.

20. Janz NK, Mujahid M, Chung LK, Lantz PM, Hawley ST, Morrow M, et al. Symptom experience and quality of life of women following breast cancer treatment. J Womens Health (Larchmt). 2007;16(9):1348-61.

21. Nissen MJ, Swenson KK, Ritz LJ, Farrell JB, Sladek ML, Lally RM. Quality of life after breast carcinoma surgery: a comparison of three surgical procedures. Cancer. 2001;1(91):1238-46.

22. Chae YR, Seo K. Health-related quality of life in women with breast cancer in Korea: do sociodemographic characteristics and time since diagnosis make a difference? Oncol Nurs Forum. 2010;37:E295-303.

23. Park JH, Jun EY, Kang MY, Joung YS, Kim GS. Symptom experience and quality of life in breast cancer survivors. J Korean Acad Nurs. 2009:39:613-21.

24. Ahn SH, Park BW, Noh DY, Nam SJ, Lee ES, Lee MK, et al. Health-related quality of life in disease-free survivors of breast cancer with the general population. Ann Oncol. 2007;18:173-82.

25. Landis JR, Koch GG. The measurement of observer agreement for categorical data. Biometrics. 1977;33:159-74.

26. Weir JP. Quantifying test-retest reliability using the intraclass correlation coefficient and the SEM. J Strength Cond Res. 2005;19:231-40.

27. Lee CF, Ng R, Luo N, Wong NS, Yap YS, Lo SK, et al. The English and Chinese versions of the five-level EuroQoL Group's five-dimension questionnaire (EQ-5D) were valid and reliable and provided comparable scores in Asian breast cancer patients. Support Care Cancer. 2013;21:201-9.

28. Lang HC, Chuang L, Shun SC, Hsieh CL, Lan CF. Validation of EQ-5D in patients with cervical cancer in Taiwan. Support Care Cancer. 2010;18:1279-86.

\section{Submit your next manuscript to BioMed Central and we will help you at every step:}

- We accept pre-submission inquiries

- Our selector tool helps you to find the most relevant journal

- We provide round the clock customer support

- Convenient online submission

- Thorough peer review

- Inclusion in PubMed and all major indexing services

- Maximum visibility for your research

Submit your manuscript at www.biomedcentral.com/submit
Biomed Central 